\title{
SELECTING THE CASE STUDY FOR RESEARCH IN NURSING SCIENCE
}

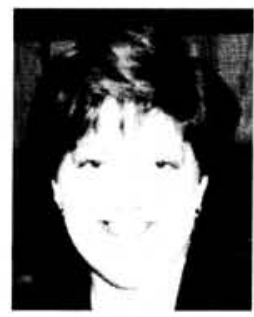

Marita Naude RN, Ph.D

Senior Lecturer: Dept. Nursing MEDUNSA

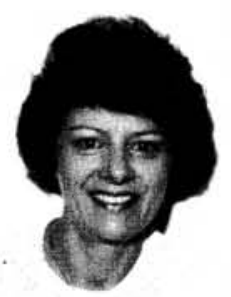

Marie Muller RN Ph.D

Professor of Nursing

Rand Afrikaans University

\begin{abstract}
The case study is an important research method to be utilised in nursing science, reflecting the reality of the phenomenon under study. The researcher should be able to select the correct type of case study, depending on the nature and scope of the research undertaken. There are several advantages and disadvantages to be considered and the researcher should ensure trustworthiness by implementing the most applicable control measures to minimise the threats in this regard. This article explores and describes the case study method in nursing research.
\end{abstract}

\section{OPSOMMING}

Die gevallestudie is ' $n$ belangrike navorsingsmetode wat in verpleegkunde gebruik kan word wat die realiteit van die verskynsel wat ondersoek word reflekteer. Die navorser behoort in staat te wees om die mees toepaslike tipe gevallestudie te selekteer, op grond van die aard en omvang van die studie wat onderneem word. Daar is verskeie voor-en nadele wat oorweeg moet word en vervolgens moet die navorser die vertrouenswaardigheid van die studie verseker deur die mees toepaslike beheermaatreëls te implementeer wat bedreigings in hierdie verband kan verminder of uitskakel. Hierdie artikel verken en beskryf die gevallestudie as navorsingsmetode in verpleegkunde.

\section{INTRODUCTION}

The reality in nursing practice is a very important research field in nursing and often requires the utilisation of the case study as the most appropriate research method at a given time, either to generate new knowledge or to validate existing knowledge. The aim of this article is to explore and describe the case study as a research method in nursing science.

Yin (1989:23) defines the case study as “... an empirical enquiry that investigates a contemporary phenomenon within its real life context, when the boundaries between phenomenon and context are not clearly evident; and in which multiple sources of evidence are used." Yin (1989:20) states that in a case study the "how" and the "why" is asked about a contemporary set of events, over which the researcher has little or no control. To enable the researcher to gain precision in formulating the questions for investigation, a literature review should be done on the topic. Merriam (1988:xii) states that qualitative case studies focus on a wholistic approach to gain an indepth understanding of a specific situation and the people involved. The interest and focus of the researcher is on the process rather than the outcome and in the discovery rather than confirmation of knowledge. Merriam (1988:11-14) also describes four essential characteristics of the case study namely particularistic, descriptive, heuristic and inductive. These essential characteristics are briefly elucidated.

\section{CHARACTERISTICS OF CASE STUDIES}

The particularistic, descriptive, heuristic and inductive features or characteristics of the case study are of importance and the researcher should be able to distinguish clearly between them.

\section{Particularistic}

The case study focuses on a particular situation, event, programme or phenomenon and therefore makes it applicable to the investigation of practical problems.

\section{Descriptive}

The end product is a rich description of the phenom- 
enon under study. It includes a complete, literal description of the incident or entity being investigated. Case studies include many variables over a period of time and can be longitudinal. It presents documentation of events, quotes and samples and are wholistic and lifelike.

Olson (in Merriam, 1988:14) lists several aspects that address the descriptive nature of the case study namely, that it illustrates the complexities and the influence of personalities on the situation, include vivid material, like quotations from interviews; obtain and present information from a wide variety of sources and from the viewpoint of different groups.

\section{Heuristic}

This indicates that the case study broadens the researcher's understanding of the phenomenon under study because previously unknown variables and relationships can emerge that leads to the rethinking of the phenomenon being studied. The heuristic quality of a case study is illustrated as it can achieve the following:

* explain the reasons and the background of a situation;

* explain why an innovation is effective or ineffective and

* discuss and evaluate alternatives and therefore increase the potential applicability (Merriam, 1988:14).

\section{Inductive}

Inductive implies that generalisations, concepts or hypotheses emerge from the examination and interpretation of data grounded in the context of the case study itself.

\section{TYPES OF CASE STUDIES}

Yin (1989:45-55) describes four main types of case studies namely, the single-case (wholistic), single-case (embedded), multiple-case (wholistic) and multiplecase (embedded) study.

In a single-case study there is a single unit of analysis whereas in a multiple case study there are multiple units of analysis. Wholistic studies examine the global nature of the aspect/topic under study. The underlying theory is also wholistic in nature. In embedded studies different sub-units of analysis are identified and studied. Analysis can also include the outcomes from individual projects within the study (case).

\footnotetext{
ADVANTAGES OF CASE STUDIES

According to Wilson (1989:143), Burns and Grove (1993:300), Yin (1981:98) and Cresswell (1994:162:163) the case study has the following advantages:

* it can be used in relatively unstudied areas of investigation to stimulate insight and suggest hypotheses or directions for further research;
} qualitative research occurs in natural settings. The researcher can therefore explore and describe a specific topic within a specific natural setting (such as the nursing unit in a nursing service);

* the data from a qualitative study are descriptive through words, rather than numbers with the focus on participants perceptions and experiences. The researcher can therefore focus on the experience of a specific sample (such as the nursing unit managers);

* qualitative research focuses on the process as well as the outcome (product);

* data is interpreted in the context of a case rather than making generalisations. The main aim of the researcher should thus be to interpret findings within the context of the case study and not attempt to generalise to other populations or settings;

* objectively and truthfulness is based on a process of trustworthiness and verification. Strategies for trustworthiness which could be used are described by Lincoln and Guba (1984), Merriam (1988) and Yin (1989). These strategies for trustworthiness are described later in this article;

* during qualitative research, the researcher is not interested in causal laws, but in people's beliefs and experiences. The methods (such as interviews) are more subjective and do not necessarily include statistical analysis and empirical calculation. Phenomena are viewed wholistically and contextually.

In a study conducted by the author, quantitative methods (such as questionnaires) were successfully combined with qualitative methods (such as narrative sketches and unstructured interviews). The combination of these different research methods also increased the trustworthiness of the research as part of triangulation, as different data methods were implemented. (Implementing multiple data methods is one of the strategies to enhance the truth value - which includes triangulation - of a specific research study). 


\section{Disadvantages of case studies}

There are, however, also certain disadvantages of the case study as a research method. Wilson (1989:144) and Yin (1989:21-22) mention the following disadvantages:

* $\quad$ there are problems with the generalisality. Any researcher should therefore explore and describe a specific aspect or topic within a specific situation or context (such as a nursing unit) and among a specific population (such as nursing unit managers). The aim is therefore not to generalise;

* the methods for compiling case study data are not very rigorously described and can be perceived as ambiguous. This ambiguity can be limited by describing and implementing protocols for data collection and data analysis. These protocols are the specific steps to be implemented by the researcher (and the field workers) and the circumstances under which data collection and data analysis should be done;

* researchers have very little guidelines on how much data is enough. In all research studies data should only be collected until saturation of data;

* data are collected by the researcher after a relatively long-term and close association between the researcher and the participants that can lead to researcher bias influencing the finding and conclusions. Bias by the researcher is limited by the implementation of credibility strategies of trustworthiness and by explicitly describing the metatheoretical, theoretical and methodological assumptions for the researcher (and the research team) at the outset of the research study.

\section{PLANNING AND IMPLEMENTATION OF THE CASE STUDY}

To plan and implement the case study as a research method, the specific steps as described by Wilson (1989:143-145) and Merriam (1988:41-49) can be utilised. According to Wilson (1989:143), case studies are more flexible, open and vulnerable to bias than other strategies because the researcher makes judgements regarding sources, amount and credibility of data. The planning and implementation of the case study is done without many rules. To provide structure and enhance the credibility of the case study, the following steps should, however, be followed:

* Determine the purpose of the case study.

* Identify the unit of analysis.

* Determine the selection of data sources.

* $\quad$ Specify the data collection plan and methods.

* Analyse and interpret the data.

* Prepare a report on the conclusions and outcomes.

\section{a) Determine the purpose of the case study} Yin (1989:25) states that there are four applications for case studies, namely to: tions that are too complex for surveys;

* describe the real-life context in which an intervention has occurred;

* explore situations in which the intervention has no clear, single set of outcomes;

* evaluate a specific intervention.

In any case study the purpose (or aim) of the case study should be described explicitly and clearly during the planning stage of the study. For example: The aim of this study is to explore and describe a model for transformational leadership by nursing unit managers to facilitate individual and nursing unit transformation. Objectives to achieve the described aim can also be formulated to provide more structure to the study.

\section{b) Identify the unit of analysis}

Merriam (1988:44) states that the unit of analysis can be an individual, a programme, an institution, a group or an event. These units of analysis should be stated, for example: the units of analysis can be as follows:

* individual: the leader and the followers;

* group: group or followers in the nursing unit and

* organisation: nursing unit within a nursing service.

\section{c) Determine the selection of data meth- ods and sources}

The data sources (participants) for a study are selected according to the sampling method and the sampling criteria described. In any case study the researcher therefore states and justifies the sampling population (for example the nursing unit managers in a specific nursing service) and the sampling method to be utilised. Usually in the case study method purposive sampling is used as it allows the researcher to select participants best suited to the aim of the case study. To prevent bias in the selection of the participants the researcher should state selection criteria to be adhered to when selecting the sample.

Merriam (1988:48) states that purposive sampling is based on the assumption that the researcher wants to discover, understand and gain insight. The researcher therefore selects a sample from which the most information can be collected. The data-collection plan, methods, analysis and interpretation should be specified. In the collection of data the researcher should decide which method is the most appropriate to reach the aim of the study. Quantitative methods (such as questionnaires) or qualitative methods (such as narrative sketches, semi-structured and/or unstructured interviews) can be utilised. These methods should be combined to enhance the trustworthiness of the case study. 
When implementing a selected research method the researcher should adhere to the strategies for validity and reliability (for quantitative methods) and the strategies for trustworthiness (for qualitative research) for that specific selected method.

\section{d) Prepare a report on the outcomes}

According to Yin (1981:64), a case study report is usually a lengthy narrative without a predictable structure. Structure can, however, be provided if the study is built on a clear conceptual framework. The aspects/phenomena explored and described in the conceptual framework form the theoretical framework for the case study. The author experienced that it was easier to utilise the same headings and subheadings which were utilised in the conceptual framework for the study as the headings and sub-headings of the case study. For example: if in the conceptual framework the nursing unit manager was described as a clinical practitioner, a transformational leader and a researcher, the analysis of collected data should also be described within this framework. The case study report can be in the format of a research report, a manuscript, a dissertation or a thesis - this depends on the purpose of the research which could include the case study strategy as part of the whole study.

The case study report can also be presented as a multicase report with separate sections of the report devoted to the individual cases (such as nursing units). According to Yin (1989:134), a multi-case report is when the report contains multiple narratives. In addition, the multi-case report includes a cross-case analysis. In the cross-case analysis the data collected during the case study are utilised to correlate aspects, issues, experiences and/or viewpoints between the participants in the different sections. For example: A cross-case analysis can be done between four nursing units which were included in the case study. This should however be well planned from the start of the study as data should be collected on the same issues or aspects and the circumstances for the data collection sessions should be similar. It is therefore imperative that the researcher utilises research protocols which describe the steps to be implemented by the researcher (and the field workers) in the process of data-collection and data-analysis.

The researcher can also utilise a linear-analytic and chronological structure for the report. Yin (1989:137 -139) describes a linear-analytic structure as a report where a "... sequence of subtopics involves the issue or problem being studied, the methods used, the outcomes from the data collected and analyzed, and the conclusions and implication from the outcomes." This type of structure is applicable to descriptive and exploratory case studies. The chronological structure is "... to present the case study evidence in chronological order." This structure can also be used for exploratory and descriptive case studies.

For example: when implementing questionnaires the researcher should adhere to the criteria for validity of questionnaires (such as face and content validity). In the analysis and quantification of the questionnaires, the researcher should still adhere to the basic principles of quantification and statistics. When implementing narrative sketches, the researcher should also adhere to the criteria for the data collection session of a narrative sketch and also to the basic principles for the analysis and interpretation of unstructured data (such as the principles stated by Tesch, 1990 in Cresswell, 1994).

It is therefore imperative that the researcher describes specific protocols for each data-collection and data-analysis session implemented in the case study. (This aspect was also discussed earlier in this article).

In the planning of the case study, the researcher should ensure that the methods implemented for data-collection enhance and support each other. It is also very important to remember that the role of the researcher is different during the implementation of each of the selected methods.

The role of the researcher in case study research The role of the researcher in case study research needs to be clarified. According to Burns and Grove $(1993: 80)$ the use of the self is an important factor in the process of qualitative research. Merriam (1988:36) confirms this by stating that "the investigator is the primary instrument for gathering and analysing data". The researcher should respond to the situation by maximising opportunities for collecting and producing meaningful information by keeping an open mind during the data collection and data analysis process. This is also supported by Mouton and Marais (1990:43) who state that in an exploratory study the researcher should be willing to examine new ideas and be open to new ideas and stimuli.

Merriam (1988:38) mentions sensitivity to the physical setting, the people and the communication between the people as an important factor. The researcher should also be a good communicator by establishing rapport, asking questions and listening intensively. Empathy and trust are the foundation of rapport.

One of the strategies recommended by Burns and Grove (1993:34) to facilitate openness, is the deliberate suspension of previous knowledge or bracketing. This is done by the researcher to allow new knowledge and perspectives on the topic of research. In order to achieve effective bracketing continual selfevaluation is needed by the researcher. 
Merriam (1988:37) mentions that the case study researcher should have a enormous tolerance for ambiguity as the researcher should be able to adapt to unforseen events and also change direction in the pursuit of meaning. In any study the researcher should be guided by the objectives and the outcomes of each contact session. To enable the researcher to determine the direction for the case study the data collected during each contact session should be analysed as soon as possible after the collection thereof. Planing for the next contact and direct observation sessions is then done.

Mouton and Marais (1988:82) state that where the researcher is seen as a stranger or an intruder who interrupts the normal activity, this image of the researcher can effect the outcome of the study. Therefore, the researcher should build rapport with the participants in the study.

Other aspects in the role of the researcher depends on the research method utilised by the researcher. For example: during direct observation and/or interview sessions (contact sessions) the researcher should listen attentively, show interest and empathy. Feedback is encouraged by using specific interview skills, such as paraphrasing, head nodding. Minimal questions are asked by the researcher. The contact sessions are conducted in a general atmosphere of freedom of expression to encourage participants to openly discuss their opinion. A non-judgemental and unbiased attitude are adopted by the researcher.

Only data that is absolutely necessary to reach the objectives of the study are collected. Data are only collected until saturation of data is reached. The primary role of the researcher in a case study is that of a data collector. It therefore necessitates the identification of personal values and assumptions at the outset of the study. The researcher should therefore describe the metatheoretical, theoretical and methodological assumptions for the study at the start of the study.

The role of the researcher also includes the obligation to respect the rights, needs, values and desires of the participants. The researcher should thus adhere to acceptable ethical considerations for research. An example of such acceptable theoretical considerations are described by the policy memorandum by the South African Nursing Association (1991). This memorandum comprises aspects like consent from the participant, privacy, confidentiality and anonymity and provides a good basis to the case study researcher.

\section{TRUSTWORTHINESS OF THE CASE STUDY}

To establish and maintain trustworthiness for a case study, the model of Lincoln and Guba (1984) can by utilised. The specific suggestions of Merriam $(1988: 166$ - 170) and Yin(1989:95-103) on the trustworthiness of case studies are also considered.

\section{a) Truth Value (Credibility)}

Truth value addresses the question whether the research has established confidence in the truth of the findings and deals with the question of how the researcher's findings match reality. One of the assumptions of qualitative research and also of naturalistic inquiry is that reality is wholistic, multidimensional and ever-changing. The case study worker should therefore attempt to portray the world as it appears to the people in it (Merriam 1988:167). Specific strategies can be implemented to enhance truth value. One of these strategies is triangulation. Triangulation includes the utilisation of multiple investigators, multiple sources of data and multiple methods to confirm the emerging findings.

\section{Multiple investigators}

Merriam (1988:169-170) suggests the utilisation of multiple investigators. Lincoln and Guba (1984:301) also support the utilisation of multiple investigators for triangulation. Whenever multiple investigators cannot be engaged in a study, the researcher should utilise different independent researchers at different phases of the study to enhance the trustworthiness. An independent researcher is utilised to validate the analysis and interpretation of the results. The researcher should also use an external, independent coder to assist with the data analysis.

Final conclusions are decided upon after joint discussions between the researcher and the coder. To enhance the consistency of the validation of the analysis of the data, specific protocols are utilised.

\section{Multiple sources of data}

Merriam (1988:169-170), Yin (1989:95) as well as Lincoln and Guba (1984:301) support the utilisation of multiple sources of evidence to provide multiple measures of the same phenomenon. Therefore findings and conclusions made from these sources are more convincing and accurate, as it is based on several sources of information, following a corroboratory mode.

\section{Multiple methods}

Merriam (1988:169) as well as Lincoln and Guba (1984:301) propose triangulation by multiple (different) methods. This is done by implementing different methods of data collection such as questionnaires, narrative sketches, direct observation by the researcher and unstructured/structured interviews. Merriam (1988:169) suggests member checks, peer examination, longterm observation (prolonged engagement), and the clarification of researcher biases as other methods to enhance truth value. 
Member checks is when the data are referred back to the participants for evaluation and validation. It is suggested that member checks are carried out on a continuous basis throughout and at the end of the study (Merriam 1988:169). Yin (1989:44) supports this strategy as he states that the draft case study report should be reviewed by the key informants. For example: if the case study was conducted in a nursing unit with the registered nurses in charge of the nursing units as the participants, these registered nurses should evaluate the final report before publication thereof.

Merriam (1988:169) states that peer examination is where the research process and the findings are discussed with a colleague who is experienced in research. The researcher conducting the case study should therefore select and utilise an experienced and credible researcher for this purpose.

Merriam (1988:169) as well as Lincoln and Guba (1984:301) advise longterm observation (prolonged engagement) to enhance the truth value of a study. Prolonged engagement is when data are collected over a period of time in order to increase the validity of the outcomes. The researcher should spend an extended period of time with the participants to allow the researcher to check perspectives; to allow the participants to get acquainted with the researcher; and for mutual trust to develop.

Lastly, Merriam (1988:170) states that researcher's biases should be clarified. Researcher's biases are clarified by stating the researcher's assumptions and theoretical orientation at the outset of the study. These assumptions include the metatheoretical, theoretical and methodological assumptions of the researcher conducting the case study.

Yin (1989:99-103) adds the creating of a case study data base and maintaining a chain of evidence as strategies to enhance the truth value (validity) of case studies. Notes are likely to be the most common component of a data base. These notes take a variety of forms and should be stored in such a manner that they can be retrieved efficiently by the researcher and also by any other person. Notes should be divided into groups/categories and sub-categories. To maintain a chain of evidence means that an external observer (any reader of the case study) can follow the derivation of any evidence from the initial research questions to the ultimate case study conclusion. The external observer should be able to trace the steps from the conclusion back to the research questions and then back to the conclusion (Yin 1989:301). Yin (1989:103) suggests the following strategies to maintain a chain of evidence:

* the case study report should make sufficient citation of the case study data base. The researcher should therefore provide a rich, de- tailed description of all strategies utilised and the evidence obtained during the case study. Evidence is supported by means of direct quotations from the case study data base;

* the data base should reveal the actual evidence and also include and indicate the circumstances under which the evidence was collected. It should be evident that the data collection followed the procedures stipulated in the protocol. In all the procedures (data collection, data analysis and data validation) the compiled protocols should be implemented and adhered to.

\section{b) Transferability (Applicability)}

Merriam (1988:173) states that transferability (external validity) is concerned with the extent to which the outcomes of a specific study can be applied to other situations. It means how generalisable the outcomes of the study are. The purpose of a case study is however, not to generalise from one situation to the next but to understand the particular aspect indepth. There are certain aspects of one case study that can be applied to other case studies and the researcher has to enhance the possibility of transferability.

According to Merriam (1988:177) the researcher can improve the transferability of a study be providing a rich, thick description so that anyone interested in transferability has a base of information. Lincoln and Guba (1984:298) support this strategy in the statement that "to enable anyone to make a transfer, evidence should be accumulated about contextual similarity." This is attained by providing sufficient descriptive data to make similarity judgements possible. Lincoln and Guba (1984:316) also propose a thick description with the widest possible range of information to "enable someone interested in making a transfer to reach a conclusion about whether transfer can be contemplated as a possibility".

Another strategy to enhance the transferability is to establish a typicality of the case by describing how typical the programme, event of individual is compared to others, so that users can compare this with their own situation. While the outcomes of this particular case study are not generalisable, new knowledge and insight are gained into the topic under study.

Yin (1989:43-44) states that case studies rely on analytical generalisation where the researcher strives "to generalize a particular set of results to some broader theory". Generalisation is however not automatic. A theory should be tested through replication.

\section{c) Confirmability (Neutrality)}

Neutrality refers to the objectivity of data and to inter-relational confirmability. Lincoln and Guba (1984:318-319) state that a technique for establish- 
ing confirmability is the audit trail. During the audit trail an inquiry audit is conducted. The following records are included in the audit:

* raw data (field notes, auditing recordings);

* data reduction and analysis products (condensed notes, quantitative summaries);

* data reconstruction and synthesis products (outcomes and conclusions); process notes (procedures, designs, strategies); materials related to intention and dispositions; instrument education information (pilot forms, survey formats).

Merriam (1988:172-173) suggests the audit trail as a measure to establish the consistency (reliability) of a study. It is added that the audit trail also includes the detail on how the data are collected, how categories are derived and decisions are made through inquiry.

\section{d) Consistency (Reliability)}

Merriam (1988:170-171) states that consistency refers to the extent to which the researcher's outcomes can be replicated. Qualitative research does not seek to isolate the laws of human behaviour, but to describe and explain the world according to those living in that world. As there are many interpretations to happenings, studies cannot be repeated directly.

Merriam (1988:170-172) is of the opinion that the researcher should implement the following strategies to enhance consistency:

* the researcher's position: the researcher should explain the assumptions and theory for a study;

* triangulation: this aspect of triangulation is discussed earlier in this article (see "truth value");

* audit trail: this aspect of audit trail is discussed earlier in this article (see confirmability).

Miles and Huberman (1984) identifies characteristics that are necessary to assess the trustworthiness of the researcher, namely:

* the degree of familiarity with the phenomena and study setting;

* a strong interest in conceptual or theoretical knowledge, and the ability to conceptualise large amounts of qualitative data;

* $\quad$ good investigative skills and experience in qualitative research.

\section{ETHICAL CONSIDERATIONS}

As with any other research project, the case study should also adhere to the considerations for ethical research. The position paper of the South African Nursing Association (1991:1-5) on ethical standards for nurse researchers provides a good basis for utilisation in the case study method also. The following principles are applied.

\section{a) The quality of the researcher}

The researcher and the research team adheres to the highest possible standards and do not attempt aspects beyond their capabilities (knowledge, skill and experience). The researcher should approach the study with integrity and try to remain aware of personal biases and values. The metatheoretical, theoretical and methodological assumptions for this study and of the researcher should be described early in the study. The case study is also done honestly, without fraud, acts of bad faith or misconduct at any stage of the study. All findings are reported fully, without the omission of significant data and this includes aspects regarding theories, methods and research strategies.

\section{b) Confidentiality and anonymity}

Confidentiality means that any information that a participant divulges is not made public or made available to other people. When a person agrees to participate in a research study he/she waives this right because information is available in the research report. The anonymity of a person and an institution should however be protected by making it impossible to link the specific data to the participant or to the institution. Anonymity is safeguarded as all raw data should be destroyed after the final report is completed. No participant/group/institution is referred to by name.

\section{c) Privacy}

Privacy means that a person can think and behave without the possibility of private behaviour or thoughts later being used to embarrass the participant. Only enough data to reach the aims of the study are collected. Data are only collected until it becomes saturated.

\section{d) Consent}

Written, informed consent should be obtained from all participants. In the case study the aim, objectives, methods, duration, participation needed and remuneration offered in the study should be explained to the participants.

\section{e) Harm}

All known or expected side effects or harmful aspects should be discussed with the participants.

\section{f) Termination}

The study is terminated if the study no longer adheres to the standards that were formulated during the planning phase. Any participant may also terminate participation if he/she wishes, despite initially consenting to participate.

\section{CONCLUSION}

The case study method requires a researcher who is objective, flexible, well skilled in quantitative as well as qualitative research methods, open and honest and who has lots of determination and self-motivation. This researcher should also be a well organised person as the amount of data collected during a case 
study is usually enormous and should therefore be well organised through different systems (such as ordinary folders or by means of different files on a computer) to prevent chaos from prevailing. In the opinion of the author this is definitely not a research strategy for the faint-hearted researcher intending to conduct a quick and easy research study. It is however a very stimulating and rewarding research strategy to implement as the outcomes of the case study usually support and enhance each other.

\section{REFERENCES}

BRINK, HL 1993: Validity and reliability in qualitative research. Curationis, 16(2), June 1993:35-38.

BURNS, N \& GROVE, SK 1993: The practice of nursing research. Conduct, critique and utilization; second edition. Philadelphia: WB Saunders Co.

CRESSWELL, JW 1994: Research design. Qualitative and quantitative approaches. London: Sage.

LINCOLN, YS \& GUBA, EG 1984: Naturalistic inquiry. London. New-Delphi: Sage.

MERRIAM, SB 1988: Case study research in education. A qualitative approach. London: Jossey-Bass Publishers.

MILES, MB \& HUBERMAN, AM 1984: Qualitative data analysis: A sourcebook of new methods. Beverly Hills, CA: Sage.

MOUTON, J \& MARAIS, HC 1990: Basiese begrippe: Metodologie van die gedragswetenskappe. Pretoria: RGN.

NAUDE, M 1995: A model for transformational leadership by nursing unit mangers. Johannesburg: RAU (D. Cur thesis).

SOUTH AFRICAN NURSING ASSOCIATION 1991: Ethical standards for nursing research. Pretoria: SANA.

WILSON, HA 1989: Research in nursing; second edition. California: Addison-Wesley.

YIN, RK 1981: The case study crisis. Some answers. Administrative Science Quarterly, 26, March 1981:58-65.

YIN, RK 1989: Case study research. Design and methods. London: Sage. 